\title{
UPREGULATION OF CYCLOOXYGENASE SYSTEM AND GROWTH FACTORS AS PLAUSABLE MECHANISM OF ANTINUCLEROGENIC ACTIVITY OF LEAF OF PIPER BETLE Linn: A MOLECULAR INSIGHT
}

\author{
Biswajit Majumdar, Amar Kumar Sinha, Shekhar Chandra Yadav, \\ And Dilli Ram Niroula
}

\begin{abstract}
:
Allylpyrocatechol, the active component obtained from ethanol extract of leaves of Piper betle Linn at a dose of $120 \mathrm{mg} / \mathrm{kg}$ body weight was shown to be an antiulcerogenic agent. Allylpyrocatechol was isolated from PBE by column chromatographic separation followed by preparative TLC and tested in rat ulcer model. Histological studies reveal that damage in the mucosal epithelium was corrected and the disrupted epithelium (as seen in ulcer) reversed with the test compound. The cellular, molecular and biochemical factors underlying the healing of gastric ulcer, such as, growth factors (EGF, EGF-R, SMAD-4) and cyclooxygenases (COX-1 and $C O X-2)$ were observed to be up-regulated in presence of APC during healing process. All the data showed statistical significance (by one way ANOVA) when compared to the experimental control value.
\end{abstract}

Key words: Allylpyrocatechol, COX-1,2; EGF/EGF-R, Gastric ulcer, Piper betle Linn.

\section{Introduction:}

Gastric ulcer is a disease, very common worldwide. Apart from the major causative agent, H.pylori, the spiral bacteria, the next common cause of induction of gastric ulcer are the NSAIDs (Non-steroidal antiinflammatory drugs), which are very commonly taken by the people as pain-killers. The NSAIDs induce ulcer by several mechanisms, one being the involvement of free radicals by neutrophil activation. The free radical damage occurs mainly by the lipid peroxidation. There has been an accumulative evidence of the involvement of prostaglandin, cyclooxygenase $1 \& 2$, Nitric oxide, inducible Nitric oxide synthatase and different cytokines are induced or increased by gastric ulceration and might also contribute ulcer healing. There is a cross-over role of COX-1 and COX-2 with inflammatory process and ulcer healing. It is reported that several growth factors, when up- regulated, enhance the healing process of ulcer. The most widely involved growth factors being Epidermal Growth Factor (EGF), its receptor (EGF-R) and the components of TGF-pathway (eg. SMAD-4). Numbers of synthetic drugs are available in the market and are effectively used to cure NSAID-induced gastric ulcer, but all of them are reported to have several side effects. The most widely used drug, being, Misoprostol, is reported to produce diarrhea, nausea, vomiting etc. It's even not permissible for pregnant women, as Misoprostol has an abortive property. Hence, the need for a safer drug to combat against NSAID-induced gastric ulcer is yet not fulfilled that limits the usage of NSAID. Plant drugs are normally known to have lesser or no side-effects. The plant-parts, 


\section{Original Article}

which are already edible to people are even expected to be non-toxic. Hence, the ultimate finding of a drug from plant origin, which can heal the NSAID-induced gastric ulcer, enhance the COX iso-forms and the express the up-regulation of the Growth factors can lead to the development of a drug with better prospect and accessible to the common people.

\section{Materials and Methods:}

Extraction of Plant part in Suitable Solvent:

Fresh leaves (P. betle) 250 gm was dissolved in $1 \mathrm{~L}$ of $95 \%$ alcohol or $1 \mathrm{~L}$ of Ethyl Alcohol (as specified before) at $4 \mathrm{oC} \times 7$ days with change and intermittent shaking. Filter through nylon cloth. The pooled filtrate is put in the rotary evaporator under vacuum and the extract, devoid of organic solvent was isolated. It was lyophilised under pressure, to remove water content and stored at vacuum $(\mathrm{PBE}=\mathrm{P}$. betle Ethanolic extract)

\section{Isolation of compounds from PBE:}

$1.71 \mathrm{~g}$ of PBE and $50 \mathrm{ml}$ ethanol was filtered and the filtrate treated with activated charcoal $(0.1 \mathrm{~g})$ and allowed to stand overnight(to get rid of the chlorophyll pigment, filtered, concentrated in vacuum, when a dark brown sticky mass was obtained.(1.038g) (hence, $60.7 \%$ yield). $0.5 \mathrm{~g}$ of this was subjected to column chromatography over a silica gel column containing $5 \mathrm{~g}$ of silica gel and eluted with $10 \%$ methanol-chloroform and 5 fractions were collected $(\sim 50 \mathrm{ml}$ each).

Fraction 1-Concentrated in vacuum and put to preparative TLC on a silica gel plate, using 5\% EtOAc-Hexane as the solvent. The TLC band at $\mathrm{Rf} 0.7$ was scrapped from the plate and eluted with chloroform. Concentration in

\section{Cyclooxygenese System and Growth Factor}

vacuum furnished a pure compound $(8.4 \mathrm{mg})$, which was identified as Chevibetol by IR and 1H NMR Spectroscopy. (The compound was already reported.)

Fraction 2- Concentrated in vacuum and subjected to preparative TLC using 5\% methanol- chloroform as solvent. It showed a major band with a polymeric material which gave colouration with $\mathrm{FeCl} 3$ spary, indicating its polyphenolic nature. Multiple developments of the TLC plate using same solvent resolved the major band into 2 closely spaced bands with $\mathrm{Rf} 0.3$ and 0.35 respectively. They were scrapped and eluted with $20 \%$ methanol-chloroform. On concentration 2 compounds were obtained (49.2mg and $25.3 \mathrm{mg}$ respectively). The former was found to be Chevicol or Allylpyrocatechol, whereas, the latter, was shown to be unstable and gets oxidized very quickly. Spectral data showed that this compound was not reported earlier.

Fraction 4 and 5- on concentration gave $340.8 \mathrm{mg}$ and $73.0 \mathrm{mg}$ residues respectively. Positive Molisch test showed their Glycosidic nature. They didn't show any antioxidant property, Hence, no further study with them was done. Allylpyrocatechol was designated as P1 in our study.

Preparation of Drug from Different Extract:

The dose of the extracts to be given to the Rats of the experimental ulcer model, are standardized. The different standardized dosages are: $\mathrm{PBE}=120 \mathrm{mg} / \mathrm{kg} \mathrm{BW}$. The active fractions are given at a dose just similar to their percentage yields from the extracts. Hence the dose of P1 is selected as followed: $\mathrm{P} 1=2.0 \mathrm{mg} / \mathrm{kg} \mathrm{BW}$.

All of them are mixed with $2 \%$ Gum Acacia, which works as a binder and reported to be a non-toxic one. The extracts are prepared in 
distilled water as the solvent and are given by oral intubation to the Rats, using feeding cannulae $1 \mathrm{ml}$. of the prepared drugs are given each day.

Experimental Ulcer Model:

Under healing: Design of experiment: Rats: (Male Wister strain, male, wt 100-120 g.)

Group A

Group B

(5 Rats)

(5 Rats)

$1 \mathrm{ml}$ of Vehicle

( $2 \%$ gum acacia) $\mathrm{x}$

10 days, sacrificed

(Normal control)

\section{Indomethacin $30 \mathrm{mg} / \mathrm{kg}$ body wt.}

Overnight fasting, water adlibtium

Group D

(15 Rats)

$\begin{array}{lrr}\text { Group B } & \text { Group C } & \text { Group D } \\ \text { (5 Rats) } & \text { (15 Rats) } & \text { (15 Rats) }\end{array}$

Fasting overnight

Sacrificed 4Hours

without drug (extractive)

only vehicle

Treated with Drugs

(2\%Gum in $2 \%$ Gum Acacia

After Indomethacin

Administration acacia, $1 \mathrm{ml}$ )

At pre-determined doses.

(Experimental Control)

(Experimental)

Sacrificed on 7th day 


\section{Original Article}

\section{Quantification of Mucosal Injury:}

The area of mucosal damage was calculated in square millimeters and expressed as percentage of the glandular stomach according to Szabo et.al.

Preparation of Tissue Homogenate:

Rat: Stomach tissue after the weight was homogenized using a glass Teflon homogenizing tube in $50 \mathrm{mM}$ phosphate Saline Buffer, pH 7.2 under cold condition. The homogenate was centrifuged at 2000 $\mathrm{rpm}$ for $10 \mathrm{~min}$ and the supernatant, collected for Biochemical analysis.

\section{Total Protein:}

Total protein is estimated by the method of Lowry et al. Briefly, samples and standards $(1 \mathrm{mg} / \mathrm{ml} \mathrm{BSA}$ in double distilled water $)$ in different tubes are treated with $5 \mathrm{ml}$ of RA mixture $(4.8 \%$ Na-K-Tartarate, $2 \% \mathrm{CuSO} 4$ and $3 \% \mathrm{Na} 2 \mathrm{CO} 3$ in $0.1 \mathrm{~N} \mathrm{NaOH}$ at a ratio of 1:1:48 by volume). Then Phenol regent (half diluted double distilled water) is added to the reaction mixture with continual vortexing. The reaction mixture is allowed to stand for 30 minutes at room temperature and optical density is measured at $710 \mathrm{~nm}$ using water as reagent blank.

\section{Estimation of Lipid Peroxidation:}

Lipid peroxidation in the ulcer tissue was measured by quantification of the Thiobarbituric acid reactive substances produced in the tissue. The method is as discussed earlier (261).

\section{Histology of Gastric Mucosal Tissue:}

Histopathological examination of gastric tissue was done as per the method described

\section{Cyclooxygenese System and Growth Factor}

by Bancroft et al (275). The gastric tissue was immediately fixed in $10 \%$ buffered formal saline for 24 hours.

1. Tissue was washed in tap water.

2. Kept in $70 \%$ alcohol for 24 hours

3. Transferred to $90 \%$ alcohol for 24 hours.

4. Dehydrated in absolute alcohol- 3 changes for $1 / 2$ hour each.

5. Put in Xylol for clearing- 3 changes for 15 minutes each.

6. Put in molten paraffin (fresh) $\left(60^{\circ} \mathrm{C}\right.$ $62^{\circ} \mathrm{C}$ ).

7. Blocked by fresh molten paraffin. Each block was numbered.

8. The sections were cut with a Microtome with a thickness of 3-5 $\mathrm{cm}$.

9. The ribbons of sections were floated Immediately in slides containing a drop of warm distilled water and the wrinkles were removed by teasing with a needle. Slides were placed on hot plate, so that the water evaporates, paraffin melts and the sections get fixed on the slides.

HaematoxylinE and Eosin Staining Solutions:

Harris' Method (Harris' Alum
Haematoxylene):

a) Haematoxylene: Haematoxylene (5g); Absolute Alcohol ( 50cc); Ammonium/Potassium Alum (100g); Distilled Water(1000cc); Mercuric Oxide $(2.5 \mathrm{~g}) ; \quad$ Glacial Acetic Acid (20cc) $100 \mathrm{~g}$ of Potassium Alum was dissolved in 100cc of warm Distilled water. $5 \mathrm{~g}$ of Haematoxylene was dissolved in 50cc Absolute Alcohol. This mixture was added to the first mixture and brought to boil rapidly. Then $2.5 \mathrm{~g}$ of mercuric oxide was added. The whole mixture was cooled rapidly by plunging the flask into cold 


\section{Original Article}

water. When the solution was cooled, $20 \mathrm{ml}$ of Glacial acetic acid was added. The stain was filtered before using.

b) Eosin: Eosin Y (2mg); Distilled Water $(100 \mathrm{ml}) ; 1 \mathrm{mg}$ of Eosin $\mathrm{Y}$ was dissolved in $100 \mathrm{ml}$ of distilled water. Thymol was added to inhibit fungal growth.

Procedure:

The sections were de-paraffinized after warming on hot tray for 2-3 minutes. The slides were put in Xylene for 20 minutes. They were hydrated through different grades of alcohol $(100 \%, 90 \%, 70 \%, 50 \%$, and $30 \%$ ). Finally; they were kept in distilled water for 10 minutes. Haematoxylene stain was added and kept for 5 minutes. Slides were washed under running tap water for 15 minutes. Slides were passed through Alcohol gradation $(30 \%, 50 \%$, and $70 \%$ ).Eosin was added and kept for 2 minutes. Slides were kept in $90 \%$ alcohol for 5 minutes. Slides were kept in $100 \%$ alcohol for 5 minutes and finally they were kept in Xylene for 30 minutes. Mounted in DPX.

Results: Nuclei Blue Black; Cytoplasm varying shades of Pink.

Estimation of COX-1 and -2, i-NOS, IL-8RA (CXCR1), Epidermal Growth Factor and Smad- 4 Protein:

Immunohistochemistry:

Mucosal specimen were deparaffinized in Xylene followed by $100 \%$ Alcohol. Kept in Methanol+H2O2 solution $(200: 1)$ for $1 / 2$ hour. Washed in running tap water. Kept in PBS( $\mathrm{pH}$ 7.6) for 10 minutes. Slides were wiped and incubated with Blocking solution (Normal Rabbit Serum, 1:5 in PBS).Incubated with Primary antibody [

\section{Cyclooxygenese System and Growth Factor}

Cox-1(1:50); Cox-2,IL-8RA, Smad-4, EGF$\mathrm{R}(1: 100)$ in PBS] for 1 hour. Washed in PBS. Incubated with secondary antibody HRP-labeled [1:500 anti-mouse $\operatorname{IgG}$ (for Cox-1, Cox-2, Smad-4); 1:500 anti-goat IgG (for IL-8RA); 1:500 anti-sheep IgG (for EGF-R)] for 1 hour. Washed in PBS.DAB (Diamino benzidine) solution was added and kept for 40 seconds. Washed in running water. Counterstained with Haematoxylene for 2 minutes. Washed in running water. Kept in $100 \%$ alcohol for 30 minutes. Kept in Xylene for overnight. Mounted in DPX.

Immunofluorescence:

Mucosal specimen were deparaffinized in Xylene followed by $100 \%$ Alcohol. Kept in $4 \%$ p-Formaldehyed. Washed in PBS $(\mathrm{pH}$ 7.6) for 10 minutes. Kept in Triton-X for 5 minutes. Slides were washed and incubated with Blocking solution (Normal Rabbit Serum, 1:5 in PBS).Incubated with Primary antibody [EGF-R(1:100) in PBS] for 1 hour. Washed in PBS. Incubated with secondary antibody FITC-labeled [1:500 anti-sheep $\mathrm{IgG}]$ for 1 hour. Washed in PBS. Mounted in DPX.

\section{Polymerase Chain reaction:}

RNA extraction and RT-PCR analysis: Total RNA was isolated by TRIzol method (Invitrogen) according to the manufacturer's protocol. 1 gg of RNA treated with RNaseOUT ribonuclease inhibitor (Invitrogen) was used for cDNA synthesis. Reversetranscription using Superscript reverse transcriptase-II (Invitrogen) and Oligo dT (Invitrogen), to prime the reaction was carried out. PCR primers were selected to distinguish between cDNA and genomic DNA by using individual primers specific for different exons. 1 al of cDNA was amplified by polymerase chain reaction 


\section{Original Article}

using Abgene 2X PCR master mix (Abgene, UK) and appropriate primers (Refer table M2). The expression of genes such as EGF and SMAD-4were checked. For all the genes, PCR were performed for 35 cycles, consisting of an initial denaturation at $94 \mathrm{o} \mathrm{C}$ for $1 \mathrm{~min}$, then $94 \mathrm{o} \mathrm{C}$ for $30 \mathrm{sec}$, annealing temperature of the respective gene primer for $45 \mathrm{sec}, 72 \mathrm{o} \mathrm{C}$ for $1 \mathrm{~min}$ and was terminated by final extension at $72 \mathrm{o} \mathrm{C}$ for 5 minutes.

Table 1: sequences of primers used in RTPCR analysis.

$\begin{array}{ll}\text { Genes } & \text { Primer Sequences } \\ \text { EGFR-F } & \text { AAGGATGTGAAGTGTGG } \\ \text { EGFR-R } & \text { ACTTTCTCACCTTCTGG } \\ \text { Smad4-F } & \text { AAGGTGGGGAAAGTGAAC } \\ \text { Smad4-R } & \text { ATGCTTTAGTTCATTCTTGTG }\end{array}$

Statistical tests by ANOVA.

The data generated from the different set of experiments were evaluated statistically using ANOVA, to determine the significance of Mean+SEM values. Differences were considered significant at $\mathrm{p}<0.05$.

\section{Results:}

1. Ulcer index:

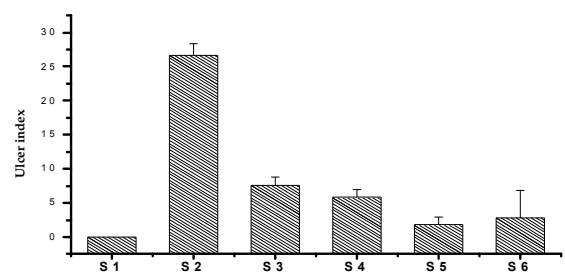

\section{Cyclooxygenese System and Growth Factor}

S1 $=$ Normal Rat Stomach; S2 = 0th Day Ulcer Rat Stomach; S3 $=7$ th Day Ulcer Rat Stomach (without treatment) S4 $=7$ th Day Ulcer Rat Stomach (treated with PBE) ;S5= 7th Day Ulcer Rat Stomach ( treated with P1) S6= 7th Day Ulcer Rat Stomach (treated with Misoprostol)

\section{Total Protein}

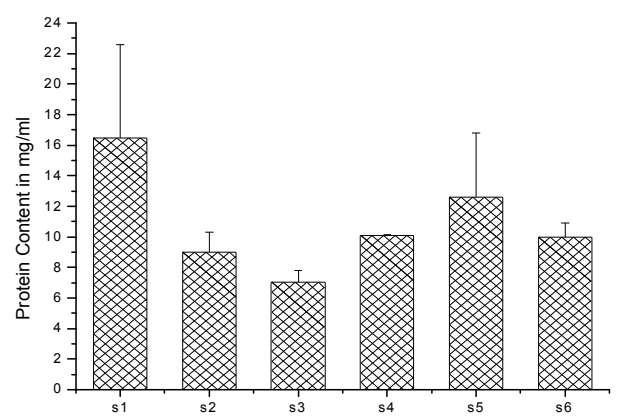

$\mathrm{S} 1=$ Normal Rat Stomach ; S2 $=0$ th Day Ulcer Rat Stomach ; S3 $=7$ th Day Ulcer Rat Stomach (without treatment) $\mathrm{S} 4=7$ th Day Ulcer Rat Stomach (treated with PBE) ; S5 $=7$ th Day Ulcer Rat Stomach (treated with P1) S6= 7th Day Ulcer Rat Stomach (treated with Misoprostol)

3. Lipid Peroxidation

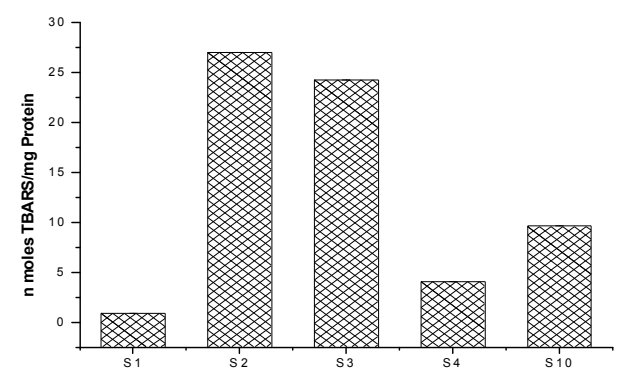

$\mathrm{S} 1=$ Normal Rat Stomach;S2=0th Day Ulcer Rat Stomach;S3 $=7$ th Day Ulcer Rat Stomach( without treatment) S4= 7th Day Ulcer Rat Stomach (treated with P1); S5 $=7$ th Day Ulcer Rat Stomach (treated with Misoprostol) 


\section{Original Article}

4. Immunohistochemistry of COX-1 and COX-2

COX-1 and COX-2 are two important factors in the induction of gastric ulcer. Though controversial, but generally it is known that COX-1 gets suppressed by the non-selective NSAIDs, forming gastric ulcer. COX-2 also gets lowered down. But in case of healing COX-1 level increases along with COX-2.

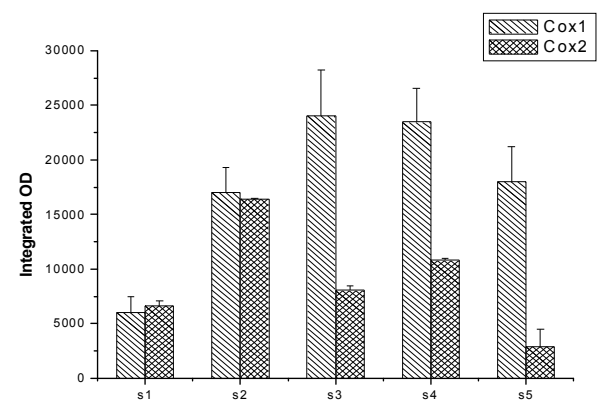

$\mathrm{S} 1=$ Normal Rat Stomach;S2=0th Day Ulcer Rat Stomach;S3 $=7$ th Day Ulcer Rat Stomach ( without treatment) S4=7th Day Ulcer Rat Stomach (treated with P1); S5=7th Day Ulcer Rat Stomach (treated with Misoprostol)

Immunohistological data showed that $\mathrm{COX}-2$ level lowers down at the onset of ulcer induction. In the 7 th day ulcerated tissue, the COX-2 gets increased but the COX-1 still remains suppressed, showing ulcerated condition, as it is known that suppression of COX-1 leads to ulcer formation. But with the extracts the COX-1 as well as COX-2 level rises. The increase in COX-1 level is much more than the rise in COX-2. The results showed that $\mathrm{P} 1$ is effective in increasing the level of both COX-1 and COX-2.

5.Estimation of EGF, EGF-R:

\section{Cyclooxygenese System and Growth Factor}

Epidermal Growth Factor is an important factor in promoting the healing effect of gastric ulcer. In a normal tissue this protein is not very significant in amount but, whenever there is an ulcer formation, the protein gets synthesized in a large amount. A good healing agent should promote the synthesis of this protein as it helps in cell division and growth of new healthy cells which replace the disrupted ones.

a. By ELISA: ELISA is a standard method to measure the binding of antibody to EGF antigen. It is quick and easy method, hence, the binding of anti-EGF antibody can prove the presence of EGF in the tissue sample.

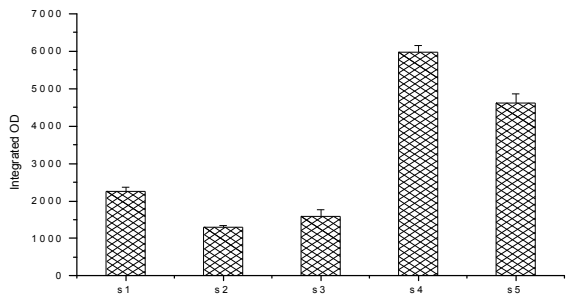

The ELISA shows large amount of EGF in the 0th day ulcerated tissue but without any treatment the 7 th day ulcer tissue showed a decrease in the EGF amount, whereas, PI showed increase in the EGF amount, suggesting the quick healing procedure, as EGF enhances the healing.

b) Estimation of EGF-R by Immunohistochemistry and Immunofluorescence:

Since, Immunohistochemistry and Immunofluorescence are two important method in showing the binding of EGF-R molecule in the gastric epidermis, they are done and the colour developed by them are measured by a software, Biovis, which measures the amount of binding by measuring the Integrated OD against the binding in percentage area of the slide. The rise in Integrated OD is a measure of high 


\section{Original Article}

binding of the antibody.

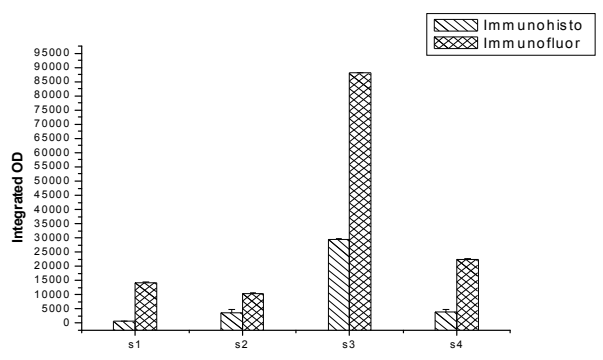

$\mathrm{S} 1=0$ th Day Ulcer Rat Stomach;S2 $=7$ th Day Ulcer Rat Stomach( without treatment);S3= 7th Day Ulcer Rat Stomach ( treated with P1) S4= 7th Day Ulcer Rat Stomach ( treated with Misoprostol);

c) Estimation of EGF-R and Smad-4 by RTPCR:

The expressions of genes were studied through PCR analysis. After the experiment DNA bands were obtained through Agarose gel electrophoresis. The result was documented by Gel Documentation instrument. The bands showed that P1 treated gastric tissue expressed EGF-R and Smad-4 gene. Misoprostol expressed EGF-R to a lesser content. On the onset of ulcer (U0) Smad-4 showed a faint band.

6. Estimation of SMAD-4 by Immunohistochemistry:

SMAD-4 protein is a component of the TGF口 pathway, which is known to increase the healing of gastric ulcer or any other tissue damage. The TGFu pathway in turn is related with the EGF regulation pathway, so activation of SMAD-4 refers to the activation of EGF regulation pathway also.
Cyclooxygenese System and Growth Factor

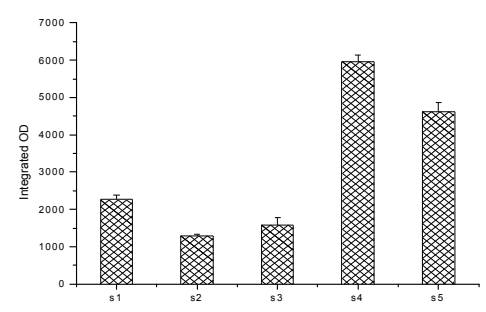

$\mathrm{S} 1=$ Normal Rat Stomach S2 $=0$ th Day Ulcer Rat Stomach $\mathrm{S} 3=7$ th Day Ulcer Rat Stomach( without treatment) S4= 7th Day Ulcer Rat Stomach ( treated with P1); S5 $=7$ th Day Ulcer Rat Stomach ( treated with Misoprostol)

Smad-4 level was decreased in the ulcer 0th day ulcer tissue, which increased in the 7 th day ulcer tissue. But the treated groups showed a good increase in the smad-4 expression. P1 proved to be the most effective in increasing the expression of Smad-4, whereas, the Misoprostol and E4 also showed a significant increase.

\section{Discussion:}

Ethanolic extract of leaves of Piper betle was shown from the similar laboratory to exhibit significant healing effect on the NSAIDinduced gastric ulcer as evident from various biochemical parameters.(ref. ). It was also shown in our previous paper that Ulcer formation, induced by Indomethacin, an NSAID, is related to the inhibition of the cyclooxygenase, that prevents the prostaglandin biosynthesis and in turn inhibits the release of the defensive factors of the stomach, mucin. The ulcer index showed that PBE gives $78.28 \%$ protection if 0 th day ulcer is taken as $100 \%$ ulcer. Whereas,P1 gives $93.41 \%$ protection; and synthetic drug gives $85.39 \%$ protection.

Results show that treatment with the extracts significantly decrease the level of lipid peroxidation product, TBARS in gastric 


\section{Original Article}

tissue compared to ulcerated rats (fig 17 and table6). The decrease in the peroxidation level of lipid indicates a plausible mechanism of free radical involvement. The peroxidised lipids are the products of ROS damage on the cell membrane leading to disintegration and de-structuring of the fluid dynamic mosaic model, leading to cell death and formation of ulcer.

NSAIDs are known to induce ulcers during the course of their anti-inflammatory action by prostaglandin synthatase inhibition (through cyclooxygenase pathway). Immunohistological data showed that COX1 and COX-2 comes to a level after a depression in cox-1 and slight increase in cox-2 level by the induction of NSAID, in the ulcerated model. On the 7th day both the COX-1 and 2 level increases. But with the extracts the cox-1 level rises much than the rise in COX-2.Recently it has been found that various gastric stressors (NSAIDs, alcohol, oxidative stressors, and acids) decrease the number of viable gastric pit cells by inducing both apoptosis and necrosis.( 295,296) Thus, increasing the number of gastric pit cells could provide a new target for anti-ulcer drugs. In fact, growth factors for gastric mucosa were shown to be effective in combating ulcers in rats by increasing the number of gastric pit cells present (297). Hence activation of SMAD group of proteins could provide the basis of new types of anti-ulcer drugs, which increase the number of gastric pit cells by inhibiting their spontaneous apoptosis and stimulating their cell proliferation.

PCR is the best method to see the expression of certain genes in any tissue. In our experiment, EGF and SMAD protein were over- expressed in the $\mathrm{P} 1$ tissue, which is a direct proof of their up-regulation during the healing by these components. The present

\section{Cyclooxygenese System and Growth Factor}

investigation thus emphasizes on the basic and fundamental research, detailing the effect of P1 in eradicating gastric ulcer. The plausible mechanism of Plbehind the healing activity can be many, including their antioxidant property, immunomodulatory property, growth factor promoting property as well as COX up-regulating property. Our study explores the possibility for the development of some new drugs from plant source that become all the more relevant for an economically weak country, like India, which is rich in natural resources. The study is based on the fact that the ethanolic extracts of Piper betle leaves accelerate the healing of gastric ulcer induced by Indomethacin. The importance of the present study multiplies as the active components of it, which is a simple molecule like allylpyrocatechol, is proved to be a very good agent in healing gastric ulcer.

\section{References:}

1. Hawkins C,Hanks GW. The gastroduodenal toxicity of nonsteroidal anti -inflammatory drugs:a review of the literature.J Pain Symptom Manage 2000;20:140-151

2. Pace V. Use of Nonsteroidal anti inflammatory drugs in cancer.Palliat Med 1995; 9:273-286

3. Coruzzi G,Menozzi A,Dobrilla G. Novel non steroidal anti-inflammatory drugs:what we have learned from animal studies.Curr Drug Targets Inflamm Allergy 2004;3:43-61.

4. 4. Garner A. Adaptation in the pharmaceutical industry with particular reference to gastrointestinal drugs and disease. Scan J Gastroenterol Suppl 1992; 193:83-89

5. 5. Dhikav V, Sing S,Pande S, Chawla A,Anand KS. Nonsteroidal drug-induced gastrointestinal toxicity: Mechanisms and Management Indian Clin Med 2003:4;315-322

6. 6. MiedererSE. Will anti-cancer drugs soon differ only in their side effects? Fortschr Med 


\section{Original Article}

$1986 ; 104: 918-920$

7. 7. Borrelli F, Izzo AA. The plant kingdom as a source of antiulcer remedies. Phytother Res 2000;14:581-591

8. 8. Yesilada E, Gurbuz I. A compilation of the studies on the antiulcerogenic effects of medicinal plants, Vol II: Phytochemistry and pharmacology .Singh S, Singh VK, Govil JN, editors. Hounton SCI Tech Publishing LLC.2003:111-174

9. Chatterjee A,Pakrashi SC. Treatise of Indian Medicinal Plants.New Delhi.CSIR Publication ,1995;26

10. Prabhu MS, Platel K, Saraswathi G, Srinivasan K. Effect of orally administered betel leaf (Piper betle Linn) on digestive enzymes of pancreas and intestinal mucosa and on the bile production in rats.Indian J Exp Biol 1995;33:752-756

11. Majumdar B, Ray Chaudhury SG, Ray A, Bandyopadhyay SK. Effect of ethanol extract of leaf of Piper betle Linn on healing of NSAID -induced experimental ulcer $-\mathrm{A}$ novel role of free radical scavenging action. Indian J Exp Biol 2003:41:311315

12. Rathee JS, Patro BS, Mula S, Gamre S, Chattopadhyay S. Antioxidant activity of Piper betle leaf extract and its constituents. J Agric Food Chem 2006; 54:9046-9054

13. Szabo S, Trier JS, Brown A, Schnoor J, Human HD, Bradford JC. A quantitative method for assessing the extent of experimental gastric erosions and ulcers. J Pharmacol Methods 1985;13:59-66

14. Esterbauer H, Cheeseman KH . Determination of aldehydic lipid peroxidation products : malonaldehyde and 4-hydroxynonenal.Methods Enzymol 1990; 186:407-421

15. Palamanda JR, Keherer JP. Inhibition of protein carbonyl formation and lipid peroxidation by glutathione in rat liver microsomes.Arch Biochem Biophys 1992; 293:103-109.

16. Burton K. A study of the conditions and mechanism of the diphenylamine reaction for the colorimetric estimation of deoxyribonucleic acid .Biochem J 1956; 62, 315-323

\section{Cyclooxygenese System and Growth Factor}

17. Luck H . Catalase. In :Methods of Enzymatic Analysis Bergmeyer HU, Editor, New York:Verlay Chemical and Academic Press.1963:885-888

18. McCord JM, Fridovich I. Superoxide dismutase.An enzymatic function for erythrocuprein (Hemocuprein). J Biol Chem 1969, 244:6049-6055

19. Corne SJ, Morrissey SM, Woods RJ. Proceedings :A method for the quantitative estimation of gastric barrier mucus.J Physiol 1974:242:116P-117P

20. Winzler RJ. Determination of serum glycoproteins. Methods Biochem Anal 1955 ;2:279311

21. Chang FY, Chen TS, Lee SD, Doong ML, Wang PS. Misoprostol -inhibited rat gastric emptying is independent of gastric inhibitory polypeptide release.Pharmacology 1999;58,265-269

22. Biswas K, Bandyopadhyay U, Chattopadhyay I, Varadaraj A, Ali E, Banerjee RK. A novel antioxidant and antiapoptopic role of omeprazole to block gastric ulcer through scavenging of hydroxyl radical. J Biol Chem 2003;278:10993-11001

23. McAlidon ME, Muller AF, Fillipowicz B, Hawkey CJ. Effect of allopurinol, sulphasalazine, a vitamin $\mathrm{C}$ on aspirin induced gastro-duodenal injury in human volunteers. Gut 1996; 38:518-524

24. Santos FA, Rao VS. 1,8-cineol, a food flavoring agent, prevents ethanol -induced gastric injury in rats.Dig Dis Sci 2001; 46:331-337

25. Bilici D, Suleyman H, Banoglu ZN A, Avel B, Ciftcioglu A, Billci S. Melatonin prevents ethanol induced gastric mucosal damage possibly due to its antioxidant effect.Dig Dis Sci 2002 : 47:856-861

26. Bhattacharya S, Subramanian M, Roychaudhury S, Bauri AK, Kamal JP, Chattopadhyay S, Bandyopadhyay SK. Radioprotective property of ethanol extract of piper betel leaf. J Radiol Res (Tokyo) 2005: 46:165-171

27. Marotta F, Tajiri H, Safran P,Fesce E, Ideo G. Ethanol related gastric mucosal damage: evidence of a free radical mediated meachanism and beneficial effect of oral supplementation with bio-normalizer, a novel natural antioxidant. Digestion 1999;60:538-543

28. El-Missiry MA, EI-Sayed IH, Othman AI. 


\section{Original Article}

Protection by metal complexexwith SOD- mimetic activity against oxidative gastric injury induced by indomethacin and ethanol in rats.Ann Clin Biochem 2001; 38:694-700

29. Szabo S, Hollander D. Pathways of gastrointestinal protection and repair :mechanism of action of sucralfate.Am J Med 1989; 86;23-31

30. Tabor CW, Tabor H. Polyamines. Annual Rev Biochem 1984; 53: 749-790

31. Wang JY, Hsieh JS, Huang TJ. Changes in rat gastric mucosal glycoproteins in portal hypertension.Eur Surg Res 1997;29:280-286

32. Rainsford KD. The effects of aspirin and other non-steroid anti-inflammatory /analgesic drugs on gastro-intestinal mucus glycoprotein biosynthesis in vivo: relationship to ulcerogenic actions. Biochem Pharmacol 1978;27:877-885

33. Naito Y, Yoshikawa T, Matsuyar K, Yagi N, Arai M, Nakamura Y, Nishimura S, Yoshida N, Kondo M. Effects of oxygen radical scavengers on the quality of gastric ulcer healing in rats.J Clin Gstroenterol

\section{Cyclooxygenese System and Growth Factor}

1995;21 Suppl 1:S82-S86

34. James AH . Gastric epithelium in the duodenum . Gut 1964; 5:285-294

35. Chang CC, Pan S, Lien GS, Liao CH, Cheng YS. Deformity of duodenal bulb, gastric metaplasia of duodenal regenerating mucosa and recurrence of duodenal ulcer a correlated study.World J Gastroenterology $2005 ; 11: 1802-1805$

36. Alanko J, Riutta A, Holm P, Mucha I, Vapaatalo H, Metsa Ketela T. Modulation of Arachidonic acid metabolism by phenopls;relation to their structure and antioxidant/prooxidant properties .Free Radic Biol Med 1999; 26:193-201

Abbreviaion Used:

APC: Allyl pyrocatechol (P1) ; COX: Cyclooxygenase; EGF: Epidermal Growth Factor; EGF-R: Epidermal Growth Factor-Receptor; MDA: Malondialdehyde; PBE: Piper betle; Linn Ethanolic extract; TBARS: Thio-barbituric acid reactive substances

Correspondence Address: Biswajit Majumdar, Associate Professor of Biochemistry, Nobel Medical College , Biratnagar, Nepal. Mobile : +977 9814333690/ +91 9007753048, E Mail :biswajitmajumdar2005@yahoo.ca; biswajitmajumdar_78@hotmail.com 